\title{
Estudos sobre partículas
}

Universidade de Brasília. Campus Darcy Ribeiro. Brasília, Distrito Federal, Brasil

Léia de Jesus Silva ${ }^{\mathrm{l}}$

Universidade Federal de Goiás. Goiás, Goiânia, Brasil

"Universidade Federal de Santa Catarina. Florianópolis, Santa Catarina, Brasil

Na introdução do dossiê "Partículas", reproduzimos o texto motivador da chamada para participação no evento Partículas, que aconteceu na Universidade de Brasília em dezembro de 2013, de autoria do Dr. Francesc Queixalós. A publicação do referido texto ${ }^{1}$ contribui para a reflexão sobre a importância de aprofundamento dos estudos sobre essa classe de palavras.

Raras são as descrições de línguas que prescindem da noção de partícula. Mais raras ainda são aquelas que fornecem uma definição da categoria que não seja ou enumerativa ('os morfemas $x, y, z$ ') ou negativa ('aquilo que não coube em nenhuma das classes identificadas até aqui'). As abordagens mais teoricistas não se saem muito melhor. As partículas têm merecido uma atenção bem menor do que outra noção problemática, a de clítico. E quando a mereceram, algumas foram assimiladas à categoria dos clíticos, outras a subclasses de subclasses de classes mais convencionais de palavras (o to do infinitivo inglês seria o único componente de uma dessas sub- sub- subclasses). Resultado: as partículas têm pouca ou nenhuma existência como ente sintático-tipológico, porém, fenômenos gramaticais continuam sendo estudados, qualquer que seja o referencial teórico, em termos de partículas.

Devemos nos perguntar se sua inconsistência formal e sua heterogeneidade funcional decorrem de uma propriedade inerente à morfossintaxe em si - ela detém regiões mais ou menos desprovidas de estrutura (a princípio, o próprio do léxico) - ou se tal situação é simplesmente fruto da incúria dos linguistas ao se depararem com os dados concretos das línguas particulares. Se for esse o caso, não podemos deixar de lembrar o desafio que encarou nos anos setenta E. Keenan acerca do sujeito (Keenan, 1976). É sabido que aquele celebrado artigo não cumpriu com o que o título prometia, pois nele simplesmente respondia-se à pergunta: o que os linguistas costumam chamar de sujeito? Mas não há dúvida de que sua proposta de inventário racionalizado e classificado apontou o rumo para o subsequente inquérito sobre a motivação funcional e as propriedades formais do sujeito.

Transposta às partículas, a empreitada de Keenan (1976) enumeraria 1) traços formais não definitórios (não exclusivos da categoria), como: acentuado, fonologicamente leve, relativamente livre, invariável, de classe fechada, com

1 Retirado do e-mail de divulgação do evento, disponível em Alves (2013).

MAGALHÃES, Marina Maria Silva; SILVA, Léia de Jesus. Estudos sobre partículas. Boletim do Museu Paraense Emílio Goeldi. Ciências Humanas, Belém, v. 14, n. 3, p. 717-719, set.-dez. 2019. DOI: http://dx.doi.org/10.1590/1981.81222019000300002.

Recebido em 05/11/2019

Aprovado em 05/11/2019
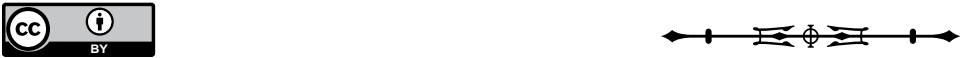
distribuição sintagmática peculiar (Wackernagel, 2009), e 2) conteúdos funcionais, tais como: estrutura informacional (foco, tópico, definitude, delimitação dos referentes), arquitetura discursiva (conexões, discurso direto/indireto), polaridade, modalidade, aspecto, tempo, fonte da informação, atos de fala (asserção, injunção, exclamação, pergunta, chamada), expressão honorífica, dêixis, classificação nominal, dependência (caso, subordinação), até 3) dicas heurísticas - muito presentes na literatura -: há partícula quando é árduo dizer se é clítico ou palavra; é difícil identificar sua função (como o doch do alemão); falta metalinguagem para a forma ou a função; seu conteúdo depende em alto grau do contexto discursivo; parece advérbio, só que com significado gramatical.

Dessa maneira, justifica-se a importância de um dossiê como este, com o objetivo específico de proporcionar uma reflexão sobre tema de tamanha relevância para os estudos sobre as línguas do mundo, apesar de ainda muito pouco discutido.

A realização do já citado evento denominado "Partículas" pelo Núcleo de Tipologia Linguística (NTL), em 2013, na Universidade de Brasília, contribuiu com o debate científico entre pesquisadores ligados a diferentes instituições de pesquisa e universidades brasileiras e é a fonte principal dos artigos deste dossiê (Congresso Internacional sobre Partículas, 2013). Também se juntaram a nós, nesta edição, pesquisadores que não participaram do evento, mas que manifestaram interesse em aprofundar a discussão.

As contribuições aqui presentes se firmam em sistemas gramaticais particulares, especialmente aqueles exibidos por línguas pouco estudadas, línguas estas que, por serem menos sujeitas ao peso das tradições de análise, favorecem a renovação dos quadros de observação. Os artigos apresentam propostas de caracterização das partículas não apenas operacionais no bojo de uma língua individual, mas também generalizáveis interlinguisticamente, num esforço comum de explicitação, aprofundamento e classificação das funções semânticas e pragmáticas das partículas.

O artigo de Francesc Queixalós contribui para a validação da noção tipológica de partícula por proporcionar análise exaustiva de um grupo particular de morfemas da língua Sikuani (Guahibo), no intuito de demonstrar sua consistência em termos de classe, sua função tipicamente gramatical e sua caracterização em termos de protótipo.

Em seu artigo, Dioney Moreira Gomes situa cuidadosamente a descrição que faz das partículas em Munduruku (Tupí) na literatura sobre o tema, analisando parte delas como clíticos, e assumindo que as partículas constituem uma classe de palavras invariáveis. Ao descrever a semântica das partículas, sua distribuição na sentença e a motivação para esta distribuição, sua conclusão é a de que esta classe é formada por itens funcionais que expressam noções discursivo-pragmáticas.

Thiago Costa Chacon, por sua vez, a partir de critérios formais e funcionais, discute as noções de palavra, morfema e sintagma em Kubeo (Tukano Oriental), a fim de definir as propriedades das partículas nesta língua do ponto de vista formal e funcional, apontando, inclusive, características compartilhadas por esta classe com outras, como a das interjeições, por exemplo, sem deixar de explicar também o que as distingue. As propriedades das partículas cuidadosamente apresentadas e discutidas no texto apontam para a análise delas como uma classe de morfemas, ao lado de outras classes, como nomes, verbos e interjeições.

Heloisa Lima Salles, num artigo que dialoga com o texto de Marina Maria Silva Magalhães por tratar da mesma língua e, em parte, do mesmo objeto de análise, e com o artigo de Quesler Fagundes Camargos, Ricardo Campos Castro e Aquiles Tescari Neto, por utilizar, também em parte, o mesmo referencial teórico, propõe uma análise da partícula tá( matá) da língua Guajá (Tupí-Guaranî), apresentando evidências e descrevendo os passos do processo de gramaticalização de uma categoria lexical verbal transitiva reanalisada estruturalmente como uma categoria funcional de Tempo (T) na estrutura oracional.

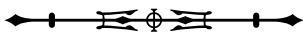


Fábio Bonfim Duarte explora, em seu artigo, a multifuncionalidade da partícula ke da língua Ka’apor (Tupí-Guaraní), orientada semanticamente para marcar definitude e animacidade em argumentos com função de objeto e afetação em argumentos com função de sujeito de verbos inergativos e transitivos, concluindo tratar-se de uma marcação de Caso inerente correspondente ao Caso dativo. Apresenta argumentos consistentes e internos à língua estudada para definir ke como parte de uma classe de partículas de Caso, que difere de outras classes de palavras e dos afixos.

Combinando harmoniosamente duas correntes da Teoria de Princípios e Parâmetros, Quesler Fagundes Camargos, Ricardo Campos Castro e Aquiles Tescari Neto apresentam, em seu artigo, a análise do que denominam Partículas de Final de Sentença (PFS) em Tenetehára (Tupí-Guaranî), um subconjunto de partículas formadas por itens que ocorrem em posição sintática rígida em final de sentença, propondo que seu ordenamento resulta da derivação, por movimentos sintáticos, a partir de uma única estrutura de base.

Ana Lívia Agostinho, Gabriel Antunes de Araujo e Eduardo Ferreira dos Santos apresentam a partícula interrogativa a da língua crioula fa d'Ambô (Guiné Equatorial), associada a uma entonação decrescente, como uma das estratégias de interrogação existentes na língua e que revela uma interface fonologia-sintaxe. Uma importante contribuição desse artigo está relacionada ao fato de essa partícula não ter sido documentada em trabalhos anteriores sobre a língua, e de os autores apontarem para a sua existência já no protocrioulo do Golfo da Guiné, uma vez que ela pode ser identificada também em outras línguas crioulas da região.

Léia de Jesus Silva apresenta as propriedades que caracterizam as partículas como uma classe de palavras em Rikbaktsa (Macro-Jê), descrevendo sua forma, função e distribuição e apresentando evidências para a distinção entre essa classe e os clíticos na língua. A autora propõe que algumas partículas podem variar em gênero e número, têm escopo sobre a proposição ou sobre constituintes específicos, têm função pragmática e, ao contrário das demais classes, que têm a propriedade de predicar (as partículas não predicam, porém, podem instituir uma oração independente).

As partículas direcionais, posicionais e de aspecto projetivo da língua Guajá (Tupí-Guaraní) são o foco do artigo de Marina Maria Silva Magalhães, que apresenta uma caracterização formal e funcional da classe das partículas, diferenciando-a das demais classes de palavras da língua, e atribuindo sua origem a distintos processos de gramaticalização a partir de verbos plenos.

O conjunto de artigos que compõem este dossiê representa uma reflexão coletiva que vai desde a observação da multifacetada realidade empírica - que encerra a diversidade das línguas - ao trabalho de organizar um inventário e sistematizar nosso conhecimento acerca dos aspectos formal e funcional daquilo que vem sendo chamado de partículas.

\section{REFERÊNCIAS}

ALVES, Flávia de Castro. [Correspondência]. Encontro Partículas. [S. l.]: 24 jun. 2013. E-mail. Disponível em: https://inguistlist.org/ issues/24/24-2558.html. Acesso em: 5 nov. 2019.

CONGRESSO INTERNACIONAL SOBRE PARTíCULAS, 2013, Brasilia. Resumos [...]. Brasília: Núcleo de Tipologia Linguística, 2013.

KEENAN, Edward. Towards a universal definition of "subject". In: LI, Charles N. (ed.). Subject and Topic. Nova lorque: Academic Press, 1976. p. 303-333.

WACKERNAGEL, Jacob. Lectures on syntax: with special reference to Greek, Latin, and Germanic. Editado por David Langslow. New York: Oxford University Press, 2009.

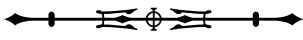


